\title{
Repair of Borderline Operable Atrial Septal Defect with Severe Pulmonary Hypertension-after Medical Management
}

\author{
Nazrin T1 , Mansur M², Jalal uddin ${ }^{3}$, Shaha N C4, Joarder M A R 5
}

\begin{abstract}
Large left to right shunt across an atrial septal defect results in volume overload and dilatation of the right atrium and ventricle. ${ }^{1}$

As a result of increased flow into the lungs, the pulmonary arteries, capillaries \& the veins are dilated \& there can be flow related pulmonary artery hypertension. Overtime this can lead to medial hypertrophy of pulmonary arteries \& muscularization of arterioles resulting in pulmonary vascular obstructive disease. ${ }^{2,} 3$ Once PAH develops, it is challenging to determine operability and predict outcomes after repair in borderline situations. ${ }^{4}$

We report a woman with large atrial septal defect and severe pulmonary hypertension 9.84 wood units $/ \mathrm{m}^{2}$ of indexed total pulmonary vascular resistance. She underwent successful corrective repair of atrial septal defect after 4 months of medical management. This case supports that careful evaluation of reversibility of borderline pulmonary arterial hypertension associated with atrial septal defect and pre operative medical management with advanced pulmonary vasodilator therapy can modify a life to normal following closure of ASD.
\end{abstract}

\section{Case Report}

A 29 years old lady, weighing $41 \mathrm{~kg}$ came to our hospital with the complaints of exertional dyspnea from 14 years of age which was aggravating for last 2 years. She denied any medical treatment before the age of 14 years when exertional dyspnea was documented. She had h/o headache and occasional syncopal attack for last 2 years.

On examination, she was dyspneic-NYHA class-III, dusky lips, $\mathrm{SPO}_{2}-95 \%$, normal precordium, LV apex, palpable P2, S1-normal, S2-narrow split, loud P2, ESM-2/6 at LUSB, 6 minutes walk test $145 \mathrm{~m}$, X-ray findings-cardiomegaly, prominent MPA, less pulmonary vascularity (Fig 1), echo cardiography showed large secundum ASD (Fig 2), moderate TR with peak velocity 5.5 /sec. Cardiac catheterization confirmed severe pulmonary arterial hypertension, total pulmonary \& pulmonary / systemic vascular resistance ratio was 0.48 . Vasoreactivity testing with oxygen showed weak response reduction in the ratio of $0.30{ }^{4}$ (Table 1, 2).

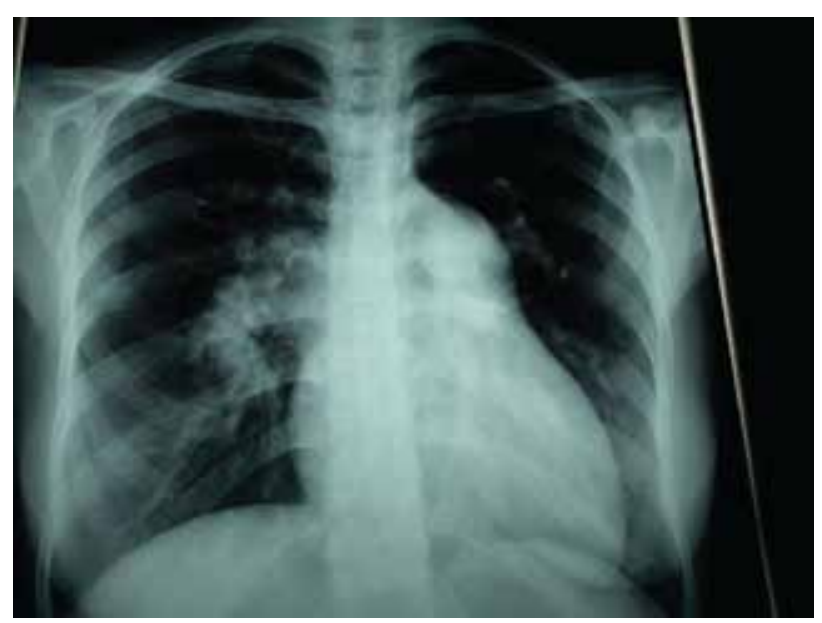

Fig 1: Preoperative X-ray chest. vascular resistance (PVRI) of 9.84 Wood Units

1. Associate Consultant, Ibn Sina Specialized Hospital, Dhaka-2. Associate Professor \& Senior Consultant, Ibn Sina Specialized Hospital, 3. Professor, Chief Cardiac Surgeon, Department of Cardiac Surgery, Ibn Sina Specialized Hospital, 4. Consultant, Cardiac \& Anaesthesiology, Ibn Sina Specialized Hospital. 5. Specialized, Cardiac Surgeon, Ibn Sina Specialized Hospital. 
Repair of Borderline Operable Atrial Septal Defect with Severe Pulmonary Hypertension

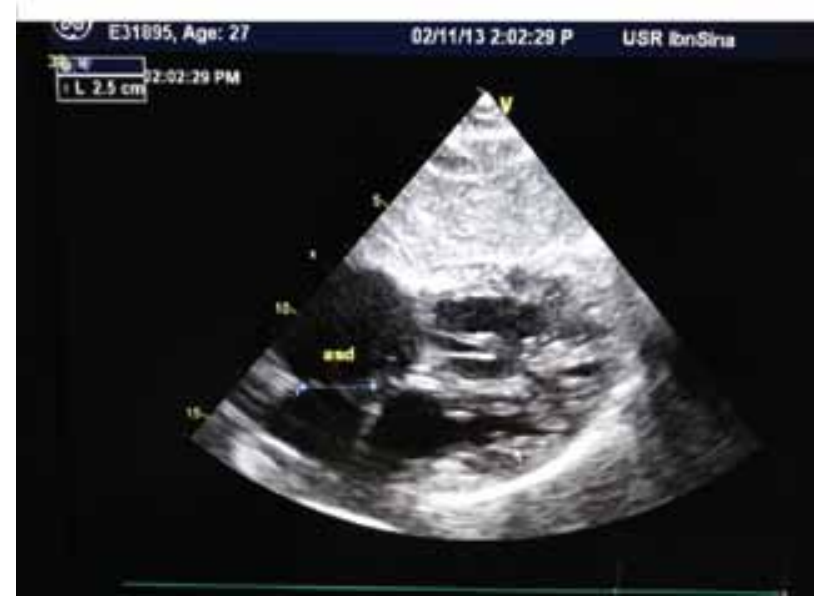

Fig 2: Preoperative echocardiogram shows large ASD.

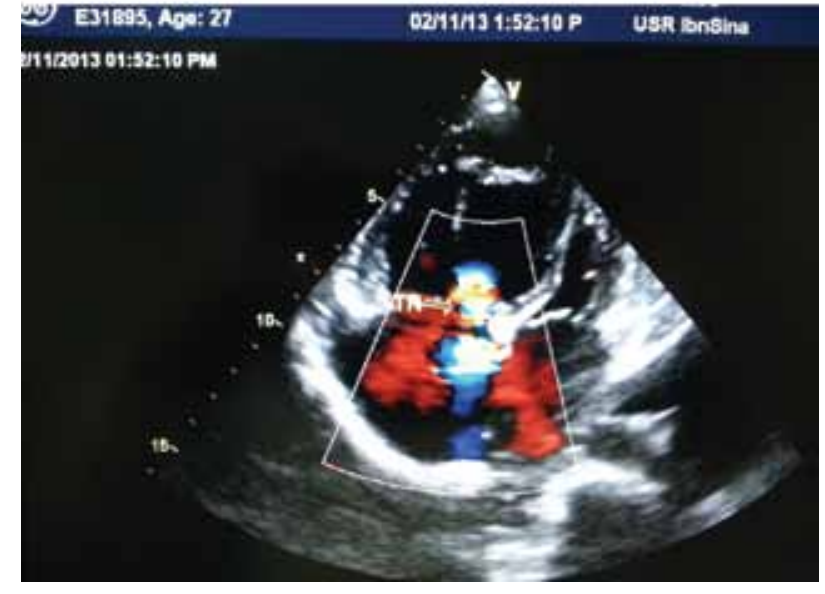

Fig 3: Severe tricuspid regurgitation (on medical treatment).

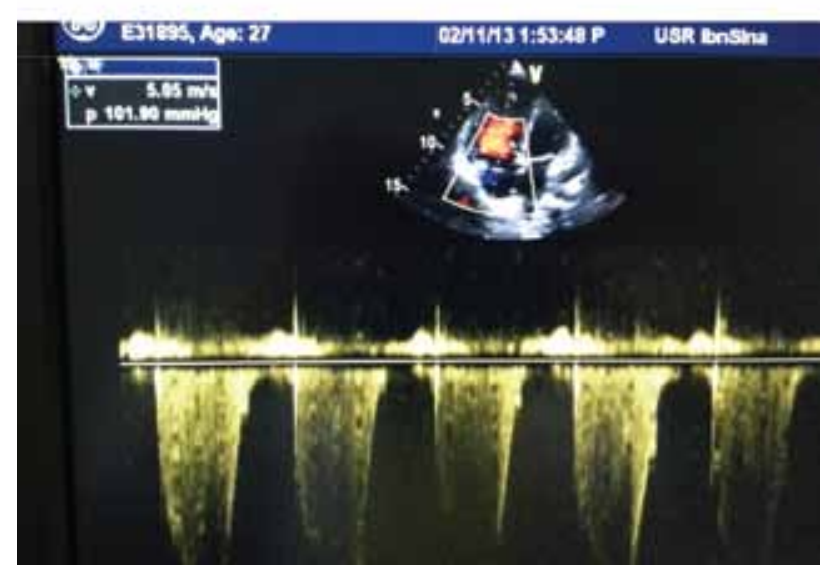

Fig 4: Severe tricuspid regurgitation (on medical treatment).

Basal Hemodynamic Data:

Table 1:

\begin{tabular}{|l|c|c|c|c|}
\hline & Pre $\mathrm{O}_{2}$ & Pre $\mathrm{O}_{2}$ & Post $\mathrm{O}_{2}$ & Post $\mathrm{O}_{2}$ \\
\hline Site & Pressure $\mathrm{mm} \mathrm{Hg}$ & Saturation $\%$ & Pressure $\mathrm{mmHg}$ & Saturation \% \\
\hline RA & $6 / 0 / 2$ & 81.8 & $7 / 2 / 4$ & 86.3 \\
\hline PA & $121 / 38 / 66$ & 82.0 & $123 / 42 / 69$ & 90.1 \\
\hline LA & $6 / 2 / 4$ & 95 & $14 / 4 / 7$ & 96 \\
\hline AAO & $122 / 62 / 82$ & 94.5 & $132 / 69 / 90$ & 96.5 \\
\hline SVC & & 70.5 & & 75.2 \\
\hline IVC & & 79 & & 84 \\
\hline
\end{tabular}

LA-Left atrium, RA-Right atrium, PA-Pulmonary artery, RV-Right ventricle, LV-Left ventricle, AAO-Ascending Aorta, SVC-Superior vena cava, IVC-Inferior vena cava. 
Table 2:

\begin{tabular}{|l|c|c|}
\hline Haemodynamic data & Pre $\mathrm{O}_{2}$ & Post $_{2}$ \\
\hline Pulmonary blood flow (Qp) & $6.3 \mathrm{~L} / \mathrm{m}$ & $10.5 \mathrm{~L} / \mathrm{m}$ \\
\hline Systemic blood flow (Qs ) & $3.9 \mathrm{~L} / \mathrm{m}$ & $4.5 \mathrm{~L} / \mathrm{m}$ \\
\hline Qp/Qs & $1.6: 1$ & $2: 33$ \\
\hline PVRI & $9.84 \mathrm{WU}$ & $5.9 \mathrm{WU}$ \\
\hline SVRI & $20.5 \mathrm{WU}$ & $19.1 \mathrm{WU}$ \\
\hline PVRI/SVRI & 0.48 & 0.30 \\
\hline
\end{tabular}

Qp- Body surface area indexed pulmonary flow, Qs-Body surface area indexed systemic blood flow, $\mathrm{SaO}_{2}-\mathrm{Arterial}$ oxygen saturation, SVRI-Body surface area indexed systemic vascular resistance, WU-Wood units.

As she was diagnosed as borderline operable case clinically and by cardiac catheterization, she was conservatively managed for 4 months with tab. Sildenafil, tab. Bosentan, tab. Enalapril, tab Frusemide. After 4 months of treatment her symptoms had improved, her dusky appearance disappeared. $\mathrm{SPO}_{2}-95 \%$ in room air, 6 minutes walking distance was $266 \mathrm{~m}$ and $\mathrm{SPO}_{2}$ improved 97\% with high flow oxygen. Echocardiography suggested that TR velocity $5 \mathrm{~m} / \mathrm{s} 5$ (Fig 3, 4).

As patient was not convinced for further cardiac catheterization she underwent surgical repair of ASD without significant perioperative problems. Although PA pressure was still high she was managed by high flow O2, inj. Milrinone, inj. Dobutamine (because of lackings of NO in our center).

Post operative period the patient's PA pressure decreased but not satisfactorily and her systemic pressure was decreased when she was on injection Milrinone. Under careful observation of vitals, PA pressure decreased slowly. After 7 days of repair TR velocity was $64 \mathrm{mmHg}$.

She gradually felt better and had no headache or chest heaviness which she had just after operation. She was on tab. Bosentan, tab Enalapril, and diuretics.

2 months after repair she presented with NYHA class II, TR velocity $42 \mathrm{mmHg}$. She is on same treatment and follow-up.

\section{Discussion}

Pulmonary hypertension is defined by a mean pulmonary artery pressure more than $25 \mathrm{mmHg}$ at rest and increased pulmonary vascular resistance (PVR) index (more than/ equal to 3 Wood Units/m 2) with a normal pulmonary capillary wedge pressure. ${ }^{6}$ Large ASD with pulmonary arterial hypertension patient frequently present with dyspnea, it is due to impaired oxygen delivery during physical activity as a result of inability to increase cardiac output in the presence of increased oxygen demand. Syncopal episodes, which occur after exertion or post exertion imply a severely limited cardiac output leading to diminished cerebral blood flow. 7

Several cases compatible with the treat and repair approach for patients with ASD and severe pulmonary hypertension have been reported. 1 Young-Hwue Kim and colleague described a 41 years old woman with large ASD with severe pulmonary hypertension with PVRI of 25.0 wood units $(\mathrm{WU}) / \mathrm{m}^{2}$. It was concluded that corrective repair was impossible \& she was conservatively managed by tab. Sildenafil $50 \mathrm{mg}$ BD. After 2 years of treatment, patient was re-examined by cardiac catheterization which revealed PVRI was $12.63 \mathrm{WU}$ $\mathrm{m}^{2} \&$ pulmonary /systemic vascular resistance ratio was 0.43 . Vasoreactivity testing with oxygen showed a reduction in the ratio to 0.24 . At 6 months after repair she presented with symptoms of NYHA class I \& echocardiography showed mild TR with peak velocity $3.8 \mathrm{~m} / \mathrm{s}$. At 1 year 8 months after repair the dose of Sildenafil was tapered to $50 \mathrm{mg}$ daily and at 3 years after repair, all medications were discontinued including Sildenafil. At the last follow-up 4 years after corrective repair, she had no symptoms and the result of 6 minutes walk distance test was $550 \mathrm{~m}$. Several cases compatible with the treat and repair 
approach for patients with ASD \& severe pulmonary hypertension have been reported.8,9 Frost \& colleagues described a 29 years old woman with near systemic pulmonary hypertension who underwent defect closure after a drop in pulmonary pressure with continuous I/V Prostacyclin. 8 Schwerzmann \& Colleagues described a 38 years old woman (PVR of $8.8 \mathrm{WU}$, reduced to $4.2 \mathrm{WU}$ with Adenosine) who showed significant symptomatic hemodynamic improvement after 1 year of treatment with intravenous Prostacyclin after which the ASD closed percutaneously. 10

Tbetze-necker and colleagues 4 described a $71 \mathrm{yr}$ old woman (PVR of 5.8 WU, reduced to 3.0 WU with NO) who showed a decrease in pulmonary pressure after treatment with Bosentan, after which the defect was surgically repaired. However, none of these 3 patients had cyanosis at baseline hemodynamic status was too dangerous to prevent corrective repair. Actually, the hemodynamic cutoff value for ASD repair is peculiar to individual institutions, leading to uncertainties about the operable criteria of ASD.

The criteria used to determine the operability of patients with ASD with pulmonary arterial hypertension include signs \& symptoms (grading of dyspnea, presence of cyanosis, $\mathrm{SP}_{2}$, palpable $\mathrm{P}_{2}$, loud $\mathrm{P}_{2}$ ), X-ray findings (Prominent MPA, less pulmonary vascularity) echo findings (severe TR with high peak velocity), cardiac cath report (revealed high PVRI with less responsiveness to oxygen, borderline PVRI \& SVRI ratio) are all indicative of a low likelyhood benefit from permanent closure. 5 According to this criteria the baseline hemodynamic findings in our patient was borderline eligible for corrective repair.

In conclusion, we experienced a case with borderline reversibility after closure of repair of atrial septal defect.

\section{Key note}

This case highlights the fact that even the borderline / clinically inoperable large ASD with severe pulmonary hypertension can be benefited from permanent closure after careful clinical evaluation and medical management. There are very few specific treatment options for these patients. Several pulmonary vasodilators are available for long term use. Phosphodiesterase-5 Inhibitors (eg. Sildenafil) and endothelin receptor blocker (eg. Bosentan) are known to improve quality of life \& actually decrease PA pressure over long term use in many patients. Other possibilities include creation of fenestration in atrial septum (atrial septal stenting or insertion of a fenestrated device) and a heart-lung or lung transplantation as a final option.

\section{References}

1. Ritu Sachdeva. Congenital cardiovascular malformtions, septal defect-atrial septal defect. In: Hugh D. Allen, David J. Driscoll, editors. Moss and Adams' Heart disease in infants, children, and adolescents including fetus \& young adult. 8th ed. Philadelphia, USA. Lippincott Williams \& Wilkins; 2013. vol 1 p. 676.

2. Haworth SG. Pulmonary vascular disease in secundum atrial septal defect in childhood. Am J Cardio. 1983;51:265-272.

3. Steele PM, Fuster V, Cohen M, et al. Isolated atrial septal defect with pulmonary vascular obstructive disease-long term follow up and prediction of outcome after surgical correction. Circulation. 1987;76:1037-1042.

4. Laksmivenkateshiah S, Kumar RK. Case studies of congenital heart disease with pulmonary hypertension: atrial septal defect. PVRI reversibility. 2009;1:186-90.

5. Venkatesan S. Reversibility of pulmonary hypertension. Archive. May 23;2012.

6. Dunbar D, Ivy. Clinical management of paediatric pulmonary arterial hypertension. chapter 67, 8th ed. 2013. vol 1 p. 1433.

7. Widlitz A, Barst RJ. Pumonay hypertension in children. Eur Respir J. 2003;21:155-176.

8. Frost AE, Quinones MA, Zoghbi WA, Noon GP. Reversal of pulmonary hypertension \& subsequent repair of atrial septal defect after treatment with continuous intravenous epoprostenol. J. Heart Lung Transplant. 2005;24:501-3.

9. Hoetzenecker k, Ankersmit HJ, Bonderman D et al. Atrial septal defect repair after a 10 month treatment with bosen$\tan$ in a patient with severe pulmonary hypertension: a case report. J Thorac Cardiovasc Surg. 2009;137:760-1.

10. Schwerzmann M, Zafar M, Mclaughlin PR, Chamberlain DW, Webb G, Granton J. Atrial septal defect closure in a patient with "irreversible pulmonary hypertensive arteriopathy”. Int J Cardiol. 2006;110:104-7. 